\title{
INFERIOR VENA CAVAL AND HEPATIC VEIN THROMBOSIS: THE CHIARI SYNDROME IN CHILDHOOD
}

\author{
BY \\ M. A. KIBEL and H. B. MARSDEN \\ From the Royal Manchester Children's Hospital
}

(RECEIVED FOR PUBLICATION FEBRUARY 23, 1956)

The syndrome of hepatic vein thrombosis was first described by George Budd of King's College Hospital, London, in 1845 . Chiari in 1899 reported three cases of his own and reviewed the literature. The first case in childhood (an infant of 17 months) was published by Gee in 1871, and since that time we have only been able to trace nine other examples of this syndrome under the age of 17 years in the world literature (Schüppel, 1880; Lazarus-Barlow, 1899; Fisher, 1902; Penkert, 1902; Fabris, 1905; Hess, 1905; Hutchison and Simpson, 1930; Thompson, 1947; Dodd, Johannsman and Rapoport, 1948; Bronte-Stewart and Goetz, 1952).

We have recently investigated a boy aged 13 years with hepatic vein thrombosis. An associated panniculitis, together with other clinical and pathological findings which throw some light on the aetiology of the thrombosis, prompted this report.

\section{Case Report}

D.C., a boy aged 10 years, had been an in-patient from September, 1952, to February, 1953, at a general hospital elsewhere, suffering from fever, debility, joint pains and tender nodules on the legs. His infancy, childhood and development before this illness had been normal and the family history was not remarkable.

No abnormality was detected clinically apart from recurrent 'erythema nodosum' on the legs. The temperature varied between 97 and $101^{\circ} \mathrm{F}$. and the E.S.R. between 17 and $27 \mathrm{~mm}$. in one hour. The white blood cell count ranged from 7,000 to 12,000 per c.mm. with a normal differential count, and the haemoglobin remained steadily at about $75^{\circ}$ o (Haldane). Frequent examinations of the urine showed no abnormalities. The Mantoux test was negative. A radiograph of the chest was normal.

During 1953 he attended school and remained fairly well with only occasional crops of erythema nodosum. In May, 1954, he was readmitted to the same hospital because of an exacerbation of the eruption and fever, a diagnosis of chronic meningococcal septicaemia being then entertained. Repeated blood cultures (aerobic and anaerobic) were, however, sterile. Cerebrospinal fluid, radiographs of the chest and agglutination tests were not informative, but the serum globulin was raised $(3.97 \mathrm{~g}$. per $100 \mathrm{ml}$.). A muscle biopsy was negative.

In March, 1955, he was admitted to the Royal Manchester Children's Hospital because of malaise, anorexia and recent loss of weight. He still had pains in the joints and tender patches on the legs, and there was occasional abdominal pain on walking. He was an intelligent, delicate-looking boy, 64 in. in height and $79 \mathrm{lb}$. in weight. Clinical examination was essentially negative apart from the eruption on the shins, thighs, calves and, to a lesser extent forearms. This consisted of rosy papules about $1 \mathrm{~cm}$. in diameter, slightly itchy on first appearing, becoming duskier over the course of 24 hours and fading over the next few days, leaving a faint purple staining with some deep induration but no superficial scarring or atrophy of the skin. The abdomen was soft and a little full, with no tenderness, free fluid or organic enlargement. The E.S.R. was $10 \mathrm{~mm}$. in the first hour and the Mantoux test strongly positive in a dilution of 1/100 (10 T.U.). The blood picture was normal.

On April 23, 1955, he complained of slight epigastric discomfort and was noted to have suddenly developed marked distension of the abdomen. There was complete anorexia but no vomiting, jaundice or constitutional upset. Tense ascites was evident, with a prominent venous network peripherally placed round the upper abdomen, particularly on the right side. The liver was enlarged four fingerbreadths, very firm but not tender. There was no splenomegaly and no oedema of the lower limbs although the pulses below the popliteals were now not palpable. Paracentesis abdominis yielded 6 pints of sterile, yellow cloudy fluid, containing $4 \%$ protein but few cells.

The suddenness of these developments, the massive ascites, hepatomegaly and absence of oedema or splenic enlargement, suggested thrombotic occlusion of the hepatic vein.

Other investigations yielded the following results: Blood urea $21 \mathrm{mg}$. per $100 \mathrm{ml}$., serum calcium $4.5 \mathrm{mEq}$. $/ 1$, serum sodium $133 \mathrm{mEq}$./1., serum potassium $4.9 \mathrm{~m} . \mathrm{Eq} . / \mathrm{l}$., serum bilirubin $0.5 \mathrm{mg}$. per $100 \mathrm{ml}$. and serum alkaline phosphatase 5 (King-Armstrong) units. The thymol turbidity was 2 units (flocculation 0 ). The serum protein level was $6.4 \mathrm{~g}$. per $100 \mathrm{ml}$. (albumin $2.8 \mathrm{~g}$., globulin $3.6 \mathrm{~g}$ ) and serum cholesterol $75 \mathrm{mg}$. per $100 \mathrm{ml}$. (free 
cholesterol $28 \mathrm{mg}$.). The urine was negative apart from large amounts of urobilin. Tests for occult blood in the stools were negative.

Radiograph of the chest, skeletal system, alimentary and urinary tract contributed nothing and an E.C.G. was normal. The Wassermann, Sabin-Feldman dye test, Paul Bunnell and other agglutination tests were all negative.

During the next few weeks he required twice-weekly paracentesis to control the ascites, and gradually developed pitting oedema of the lower extremities, abdominal wall and lower chest with increased prominence and extension of the venous network. Biopsy of a skin nodule showed a localized dense infiltration of polymorphonuclear cells confined to the fatty tissues with no overlying reaction.

On May 22, having been almost symptom-free up to this time, the patient developed sudden, severe substernal pain, dyspnoea and cyanosis. During the day there was rapid deterioration with increasing cervical venous engorgement and shortly before death a profuse petechial eruption over the chest and neck.

\section{Necropsy}

The liver was greatly enlarged and red-black with yellow areas of necrosis. Thrombi could be seen in the medium-sized branches of the hepatic veins. The inferior vena cava from just below the right auricle, up to and including the mouths of the hepatic veins, showed great thickening of the wall and narrowing of the lumen with almost complete obliteration by organized thrombus. White laminated clot with a little more recent thrombus was found to cover the mouths and extend into the channels of the hepatic veins (see figure). There were no unusual features in the portal vein, but the spleen was somewhat enlarged. Collateral circulation in the ligaments of the liver was not prominent, but the vena azygos was greatly dilated measuring rather more than a centimetre in diameter.

The entry of the inferior vena cava into the right auricle was obstructed by a thin grey membrane with tiny fenestrations in some areas. The attachment of the membrane to the circumference of the cardiac orifice was complete. Microscopic examination showed thin endothelial coverings with a central layer of cardiac muscle. There was no evidence of infiltration, whereas the walls of the veins covered by thrombus were infiltrated by polymorphonuclear and plasma cells with occasional eosinophils. Small vegetations were present in the right auricle just above the inferior vena caval opening and these were seen to be inflammatory in type with underlying cellular reaction.

Inflammation of fatty tissues was confined to the subcutaneous regions with no involvement of visceral fat. There were, however, numerous haemorrhages in the latter, in addition to many of the visceral and connective tissues. The arch and upper portion of the descending thoracic aorta were encased in blood, microscopic examination showing haemorrhage confined to the adventitia and outer layers of the media.
The capsules of the kidneys were rather adherent and there were scattered, small cortical scars. These were found to be wedge-shaped areas of fibrosis with infiltration by chronic inflammatory cells and similar areas of destruction were noted throughout the cortex, together with occasional glomerular scars.

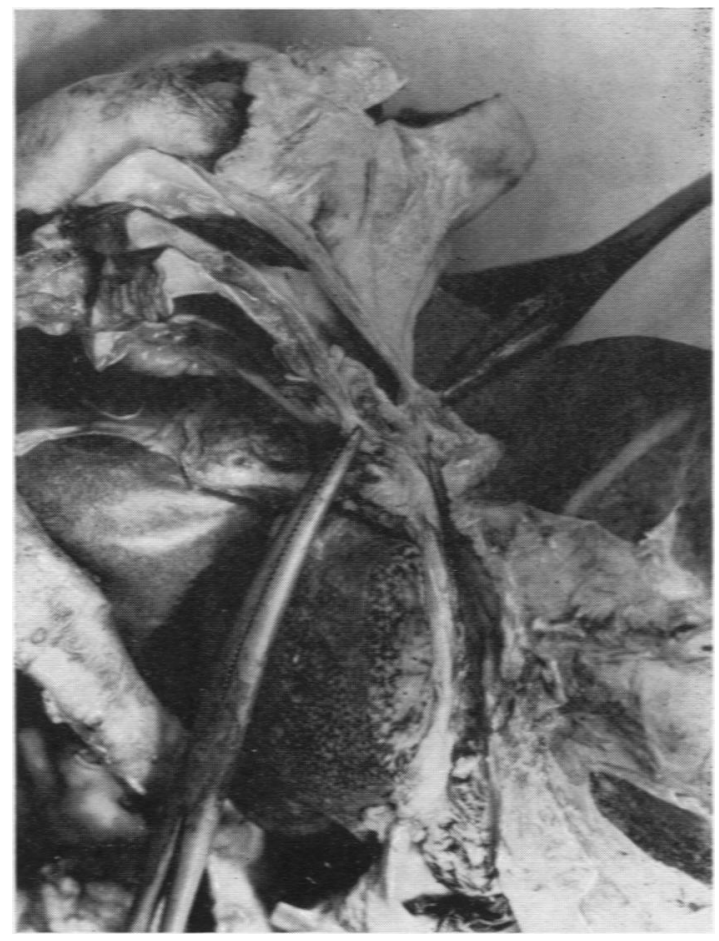

Figure.-The right auricle and inferior vena cava showing great thickening of the wall of the latter with thrombus in the lumen. The obstructing membrane described in the text can be seen between the tops of the forceps and a vegetation is present on the auricular wall just above this point. Note the areas of engorgement and necrosis on the cut surface of the liver.

\section{Bacteriology}

A staphylococcus was isolated from the right auricular vegetation and also from the thrombus in the inferior vena cava, the blood culture being sterile. As the organisms were coagulase negative and gave no reaction to typing phages, it is difficult to interpret the significance of these findings. In addition, sections stained by Gram's method failed to show the presence of organisms.

\section{Discussion}

Chiari Syndrome. When the many causes of secondary thrombosis of the hepatic vein are excluded, for example, tumours, lymphadenitis and blood diseases (Hirsh and Manchester, 1946) in which the thrombosis is merely a fortuitous phenomenon, there remains a group of cases in which the aetiology is obscure. Veno-occlusive 
disease of the liver (Jelliffe, Bras and Stuart, 1954) appears to be a distinct clinical and pathological entity in which the large hepatic veins are not involved.

The importance of congenital anomalies in the hepatic vein and inferior vena cava has been suggested. Nishikawa (1918) stated that rudimentary valves in the inferior vena cava might be concerned in the causation of the thrombosis. Bennett (1950) described a case of obstruction of the inferior vena cava by a fibrous membrane at the level of the diaphragm. The patient was 60 years of age, but the lesion was regarded as being congenital in origin. The fenestrated membrane in the present case had a central core of cardiac muscle and the covering endothelium was intact. There was no evidence of inflammation and the situation coincides with that of the Eustachian valve, a remnant of its important foetal analogue.

Hepatic vein thrombosis was suggested by the sudden enlargement of the liver, associated with the development of ascites and engorged veins over the lower chest and abdomen. This conforms with the well recognized clinical picture which has been adequately reviewed by Thompson (1947). The collateral venous channels were situated centrifugally and did not converge upon the umbilicus to form a caput medusae as is seen in portal vein thrombosis. Another differentiating feature was the absence of conspicuous splenomegaly.

The striking clinical picture contrasts with the relatively normal biochemical findings with the notable exception of the lowered serum cholesterol level. Jaundice is absent. The widespread haemorrhages in our case were attributed to terminal liver failure.

The Chronic Illness. The nature of the protracted illness characterized as it was by vague ill health, with intermittent fever, joint pains and the eruption of nodules on the lower limbs over two and a half years, posed a problem in diagnosis. Rheumatism or a disease of the collagen group, tuberculosis, brucellosis and other chronic infections were considered, but there was no adequate evidence of these conditions, either clinically or at necropsy. The hyperglobulinaemia was consistent with sarcoidosis, chronic infection or a disease of the collagen group. The absence of a murmur and frequent negative blood cultures seemed to exclude infective endocarditis. However, necropsy showed evidence of a chronic blood-borne infection in the scarred, but otherwise normal kidneys and right auricular vegetations, which were thrombotic and not degenerative in type (Allen and Sirota, 1944).
It seems, therefore, that a congenital 'valve' in the inferior vena cava, though impeding to some extent the venous return, caused no significant venous obstruction owing to the adequate collateral circulation. However, the stagnation of blood in what was virtually a cul-de-sac at the upper end of the inferior vena cava led to the development of infective thrombophlebitis and subsequently endocarditis. This marks the onset of the fluctuating pyrexial illness. Scarring in the affected vessel with caudad deposition of laminated clot continued until the mouths of the hepatic veins were occluded, producing the arresting picture described.

It seems evident from our case that a focus of infection situated in a large vein must be considered in patients with chronic bacteraemia. Furthermore the repeated negative blood cultures emphasize the difficulty of excluding such a diagnosis by this method.

The Panniculitis. The rash showed certain distinct differences from erythema nodosum. The more widespread distribution, the small size, relative painlessness, rapidity of maturation and disappearance together with the incipient necrosis and subcutaneous infiltration which was entirely neutrophil in type, all militated against this diagnosis. The picture conforms rather with the relapsing panniculitis described by Rothmann and Makai (cited by Carleton, 1949), and elaborated by Baumgartner and Riva (1945). While there is no uniformity of opinion as to the causation of this disease, it usually occurs as a sequel to infection, for example tonsillitis, phlebitis or bronchiectasis (Carleton, 1949). In a case of pannicultis described by Miller and Kritzler (1943) dental extraction was followed on two occasions by a crop of nodules. In another (Baumgartner and Riva, 1945) an attack of tonsillitis preceded a similar eruption on no less than three occasions. The blood cultures in all cases, however, have been repeatedly sterile. Impaired circulation has been considered a factor, but although this was certainly present in the lower extremities in our case, occasional nodules were found on the upper limbs.

\section{Summary}

A case of thrombosis of the inferior vena cava and hepatic veins diagnosed during life is presented and the aetiology of this condition is discussed.

The incidence of the Chiari syndrome in childhood is briefly reviewed.

The causation of an associated recurrent panniculitis is examined. 
We are indebted to Professor W. F. Gaisford for invaluable criticism, and to Dr. T. N. Fisher for permission to publish this case. Our thanks are also due to Mr. A. E. Ward for the photograph.

\section{REFERENCES}

Allen, A. C. and Sirota, J. H. (1944). Amer. J. Path., 20, 1025. Baumgartner, W. and Riva, G. (1945). Helv. med. Acta, 12, Suppl. 14, p. 3.

Bennett, I. L., Jr. (1950). Bull. Johns Hopk. Hosp., 87, 290.

Bennett, I. L., Jr. (1950). Bull. Johns Hopk. Hosp., 87, 290.

Budd, G. (1845). On Diseases of the Liver, p. 184. London.

Carleton, A. (1949). In Further Rare Diseases, p. 103. Ed. F. Parkes Weber. London.

Chiari, H. (1899). Beitr. path. Anat., 26, 1.
Dodd, K., Johansmann, R. J. and Rapoport, S. (1948). Amer. J. Dis. Child., $76,316$.

Fabris, A. (1905). Zbl. allg. Path. path. Anat., 16, 709.

Fisher, T. (1902). Bristol med.chir. J., 20, 209.

Gee, S. J. (1871). St Bart's Hosp. Rep., 7, 141.

Hess, A. F. (1905). Amer. J. med. Sci., 130, 986.

Hutchison, R. and Simpson, S. L. (1930). Archives of Disease in Childhood, 5, 167.

Jelliffe, D. B., Bras, G. and Stuart, K. L. (1954). Pediatrics, 14, 334 Lazarus-Barlow, W. S. (1899). Trans. path. Soc. Lond., 50, 146

Milker, J. L. and Kritzler, R. A. (1943). Arch. Derm. Syph. (Chicago), $47,82$.

Nishikaw, $\dot{Y}$ (1918). Mitt, med. Fak. Tokio, 20,151

Penkert, M. (1902). Virchows Arch. path. Amat., 169, 337.

Penüert, M. (1902). Virchow's Arch. path. Anat., 169, 337. Therapie, ed. H. von Ziemssen, band 8, erste hālfte, abt. 2. Leipzig. Cited by Chiari.

Thompson, R. B. (1947). Arch. intern. Med., 80, 602. 